\title{
Just-in-Sequence Technologies to Boost Automotive Supply Chain Effectiveness
}

\author{
Michail Papoutsidakis, Sotiria Michael, Aikaterini Sfyroera, George Priniotakis \\ Department of Industrial Design and Production Engineering, University of West Attica, Athens, Greece \\ Email:mipapou@uniwa.gr
}

How to cite this paper: Papoutsidakis, M., Michael, S., Sfyroera, A. and Priniotakis, G. (2021) Just-in-Sequence Technologies to Boost Automotive Supply Chain Effectiveness. Open Journal of Applied Sciences, 11, 9-19.

https://doi.org/10.4236/ojapps.2021.111A0 $\underline{02}$

Received: October 19, 2020

Accepted: December 15, 2020

Published: December 18, 2020

Copyright $\odot 2021$ by author(s) and Scientific Research Publishing Inc. This work is licensed under the Creative Commons Attribution International License (CC BY 4.0).

http://creativecommons.org/licenses/by/4.0/

\begin{abstract}
This research work deals with the management of the supply chain in the automotive industry. There are also some real trends in the automotive and supply sector based on principles of flexibility. It presents the scope of the automotive supply chain characteristics, provides an overview of the structure of component suppliers and focuses on the just-in-Sequence mode. The next part deals with the application of custom supply management and the example is presented in automotive conditions with direct customer market impulses. The last part of the paper presents a reason for the need to use information technology support tools to control the production and logistics processes of suppliers in a flexible car assembly line for a continuous flow of materials. The contribution focuses on the logistics standards in the automotive industry in terms of materials and information flows in the supply system, where their flexibility is a key factor for the effective management of their flexibility. The introductory part of the article is characterized by the traditional hierarchical structure of the supply chain and the concept of supplying the car assembly unit with pre-assembled modules from suppliers in simple sequence mode and according to the requirements of direct customer orders (custom construction). The conclusion addresses the issue of the use of information technology tools to support material flow management by suppliers directly to the automaker's assembly line.
\end{abstract}

\section{Keywords}

Logistics Systems, Car Production, Supply Chain Management, Custom Construction Principle

\section{Introduction}

Regulatory changes in the automotive sector could help companies innovate and recover after the COVID-19 crisis. Many regulations in the industry are out- 
dated and unsuitable for inventions, such as autonomous vehicles (AV), which include driverless cars and delivery trucks.

The widespread economic impact of COVID-19 is becoming increasingly clear. For many sectors, the main challenge is not only to combat the pandemic, but also to manage its economic and social consequences and to find appropriate measures to tackle them. This is particularly true of the already stressed car industry. The crisis is massively affecting liquidity, supply, production and demand. Companies had to close factories and deal with vertical sales and cut supply chains. As a result, revenue slumped around the world [1].

In many countries, the automotive industry is a key driver of GDP as well as a major employer. The problem in this sector will lead to serious challenges for the wider economy. To overcome these challenges, automakers are already seeking support and governments have responded with short-term measures, such as providing financial assistance and facilitating short-term work. However, more is needed in the medium and long term. Governments and companies should start preparing for what comes after the survival of the acute crisis. The question will change from how the crisis is managed, to its long-term impact and its potential impact on the future of industry [2].

A crucial step will be to encourage innovation. Simplifying and updating pilot and testing regulations would be a way to help companies innovate and is accompanied by the added advantage of not needing additional financial data.

The automotive sector is one of the most strictly controlled industries in the world. Many of these rules are necessary to ensure human safety and the protection of the environment. Others, however, were created to fit into an idea of cars and transportation that has since changed. A striking example of this is the emergence of autonomous vehicles (AV), such as driverless cars and delivery trucks. Existing regulations are not suitable for this emerging technology. Current safety standards, for example, require human control. In fact, any license to operate a self-driving vehicle on public roads includes exceptions to existing regulations and standards.

To make matters worse, there is no internationally recognised standard for registration and certification of self-driving vehicles. Sometimes, this doesn't even exist nationally. The 1968 Vienna Convention on Road Traffic (in the 2016 edition) still requires a driver behind the wheel. This means that driverless transport is not possible under this condition. Finally, the rules often vary from country to country, leading to a very fragmented regulatory framework. The lack of global harmonisation contributes significantly to the regulatory burden in this area and also prevents change, leaving the rules rather static.

For companies trying to innovate and bring new products to market, this rigid and fragmented regulatory landscape has led to uncertainty and unpredictability. Regulatory complexity usually increases production costs in the automotive industry. It can also slow down and stifle innovation. This remains true and becomes even more relevant in an economic crisis, when a clear path to the market is even more critical. 


\section{Problem Formulation}

To realize the great growth opportunities, which will be more important than ever, and to ensure that positive outcomes benefit society and mitigate risks, governments need to proactively shape the future of mobility.

The supply chain is a network between a company and its suppliers to produce and distribute a particular product to the final buyer. This network includes various activities, people, entities, information, and resources. The supply chain also represents the steps it takes to transfer the product or service from its original state to the customer [3].

Companies are developing supply chains to reduce their costs and remain competitive in the business landscape. Supply chain management is a critical process because an optimized supply chain results in lower costs and a faster production cycle.

A supply chain includes a series of steps to provide a product or service to the customer. Steps include moving and converting raw materials into finished products, transporting these products and distributing them to the end user. Entities involved in the supply chain include producers, sellers, warehouses, transport companies, distribution centers and retailers [4].

Items in a supply chain include all functions that begin with receiving an order to meet the customer's request. These features include product development, marketing, operations, distribution networks, finance and customer service [5].

Supply chain management is a very important part of the business process. There are many different links in this chain that require skill and expertise. When supply chain management is effective, it can reduce a company's total costs and increase profitability. If a link collapses, it can affect the rest of the chain and can be costly [4].

The terms of supply chain management and logistics management, or simply, logistics, are often used interchangeably. Logistics, which is a link in the supply chain, is different.

Logistics refers specifically to the part of the supply chain that deals with the planning and control of the movement and storage of goods and services from their point of origin to their final destination. Logistics management starts with raw materials and ends with the delivery of the finished product [6]. In Figure 1, a typical production pyramid from raw materials to OEM part assembly is provided, to illustrate that there is a constant need of management and control in the logistics process.

Successful logistics management ensures that there is no delay in delivery anywhere in the chain and that products and services are delivered in good condition. There are many ways of transportations of raw materials or goods that can be used as an assembly part, modern transportation methods are applied for the cause as sheen in Figure 2. This, in turn, helps reduce the cost of the company.

The flow of manufacturing costs refers to the process of using materials and work to complete a finished product that can be sold to a customer. A supply 
chain management system can reduce the cost and complexity of the manufacturing process, especially for a manufacturer that uses many components [7].

An efficient supply chain management process requires reliable suppliers. This means that they produce a quality product that meets the needs of the manufacturer and the product is delivered on time [8].

The development and increase in the efficiency of supply chains have played an important role in reducing inflation. As the efficiency of products increases rapidly, costs decrease as an effect, which reduces the final cost to the consumer. While deflation is often seen as negative, supply chain efficiency is one of the few examples where deflation is good. As globalization continues, the efficiency of the supply chain is optimized, which keeps the pressure on input prices.

Many countries, in particular developed countries, have also begun to set up environmental management systems, the so-called SPDs (Supplementary Planning Documents) that aim at sustainable development. The ISO (1996a) defines the SPC: "The SPC (Statistical Process Control) is an integral part of an overall management system that includes the organizational structure, planning, activities, responsibilities, procedures, procedures and resources for the development, implementation, achievement, revision and maintenance of environmental policy" [9].

In short, the SPC is the management of the environmental programs of an organization, which manages the impact of the organization's activities on the environment. The SPC provides a structured approach to the design and implementation of environmental protection measures [4].

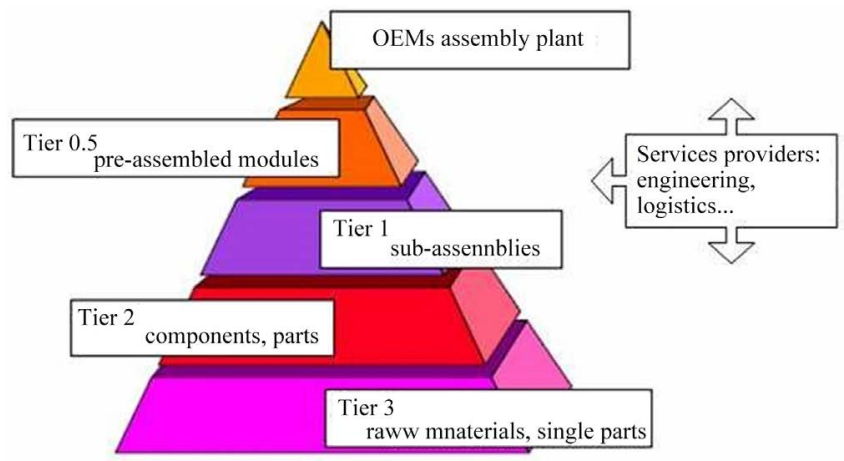

Figure 1. Typical chain flow for OEM parts.

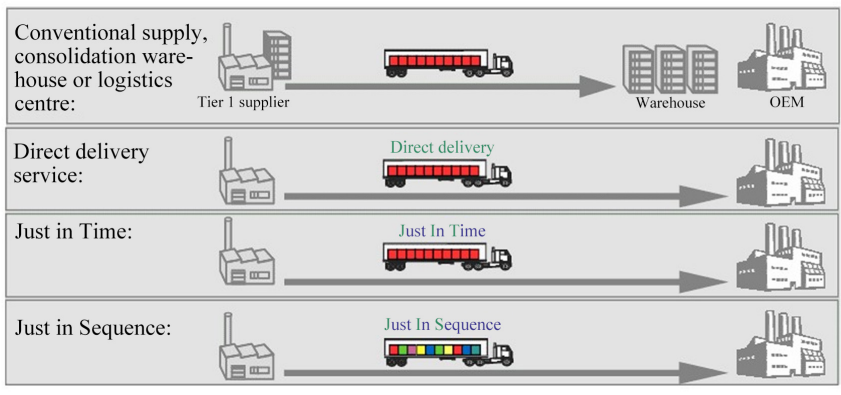

Figure 2. A chart of all types of delivery. 


\section{Problem Solution}

Since legal regulations in accordance with national and regional conditions differ from one another, different environmental standards and entities may have been developed in different countries. This complexity has begun to create a variety of barriers to trade. In order to overcome these differences between countries, the standard ENS was created. These standard EMS are as follows [4] [10] [11] [12]:

1) BS 7750, which comes from the British Institute of Standards.

2) EMAS: Eco-management and control system, consisting of European Union standards.

3) ISO14000, which consists of the International Organization for Standardization.

Intense competition, fluctuating market demand and increasing customer demands result in customers becoming more demanding with increased preferences [13] [14]. This is due to changes in the market, which are characterized by shorter product life cycles, more competitive product imports and demand volatility, which make life cycle demand more uncertain and difficult to predict [15]. The automotive industry of the 21 st century, heavily influenced by globalization, has created significant opportunities, and at the same time put pressure on manufacturers to improve quality, improve style, increase organizational efficiency and include innovative features in their products in an effort to attract customers and expand into new markets These challenges suggest that if car manufacturers wish to succeed, they must be flexible and meet customer requirements [16].

Supply chain management practices have begun to move towards more frugal process approaches in an effort to increase supply chain efficiency (reducing costs and eliminating deficiencies). Concepts such as MET; rationalization of the supplier base; virtual stock; outsourcing; adapted and global networks; reducing stocks in material, capacity and time; and a reduction in the number of distribution facilities have led to improvements in supply chain performance, in particular cost reduction. However, due to vulnerability and turbulence in the business environment, the lean supply chain can no longer cope with changing customer requirements. The characteristics of the traditional downstream supply chain (lean) do not provide for addressing the changing business environment, but minimizing low cost and waste (value flow mapping). Therefore, lean is not a universal solution to meet all supply chain needs. To achieve a high degree of flexibility and customer responsiveness, a combination of lean philosophy and new technology is required to quickly design new improved functions on the store floor and beyond [17].

The automotive industry has certainly facilitated people's lives and made many contributions to people's daily lives. Moreover, as an economic phenomenon, it has significantly affected the world economy. However, the automotive industry has also affected nature and the ecosystem. Note that total global car production reached 80.1 million units in 2011 [4]. If production goes at this 
rate, there will be about two billion cars on the road, which means more pollution, more negative effects on the environment, more energy consumption, and greater spending on the world's resources. Energy and resource shortages make car manufacturers more sensitive. Thus, environmental sensitivity will affect the automotive industry in such matters [18].

There are many significant global impacts that begin after the production phase of vehicles. However, before production, during the production steps, but also the final disposal of vehicles also causes serious environmental problems. In addition, car use consumes a huge amount of fossil fuels, which therefore leads to a serious air pollution problem, due to the many harmful substances that directly exhaust cars in the air. These emissions are carbon dioxide, carbon monoxide, nitrogen oxides, sulphur oxides, ozone, aldehyde compounds, specific hydrocarbon materials and particles [19].

The recent nuclear disaster in Japan and the huge oil spill from the drilling tower in the Gulf of Mexico are good examples of possible environmental risks that can be initiated by industries. Moreover, unstable political systems in oil producing countries), such as Libya, Iraq, Venezuela, etc., make sustainable energy sources attractive alternative sources of energy required for industry.

Automakers have faced huge challenges when it comes to environmental issues for a long time. Since 1980, despite the fact that car manufacturers have taken a positive stance on reducing the environmental impact of their production process, they still face not only problems with the environment, but also face a lack of a sustainable supply chain [20]. One of the good examples from Toyota is that lean production techniques in Toyota's production system eliminate waste from all activities and processes, but nonetheless, how end-of-life vehicles are eliminated and recycled again in an effective way still waiting to be answered. Figure 3 provides a brief view of the manufacturer's supply chain.

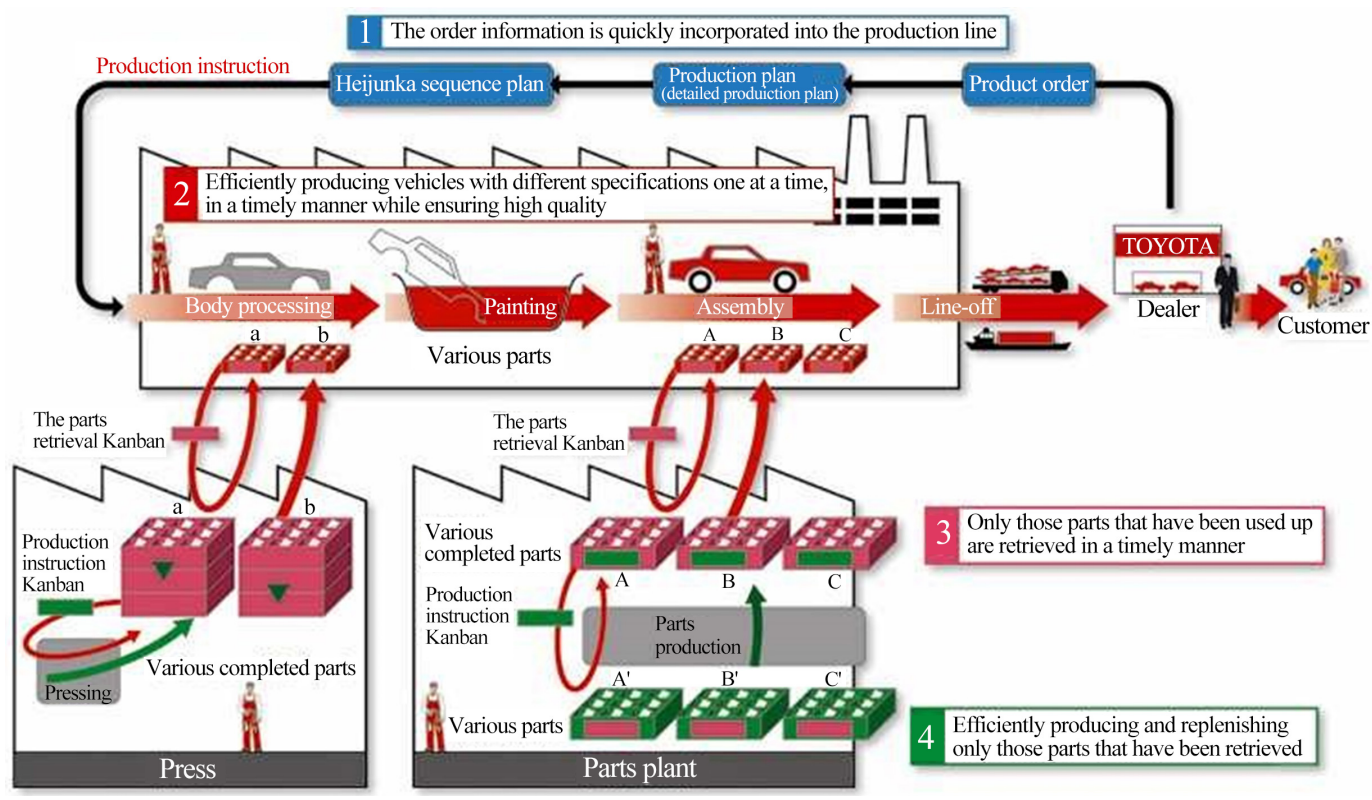

Figure 3. OEM parts effect automotive industry. 
Despite the accepted idea in the market that hybrid and electric cars are uneconomic, their implementations are good news for sustainability in the supply chain. In addition to this, Zah et al. (2007) reported that the use of natural fibres instead of glass fibres may have economic, social and environmental potential for improvement for the automotive industry. This will not only contribute to the economic benefits due to its low life cycle cost, but will also bring social benefits due to its high added value in the automotive industry [21].

On the other hand, companies are becoming more internationalist. Internationalisation and globalisation have caused cooperation with different suppliers. However, this makes it difficult to eliminate materials whether they are harmful to the environment/social or not [22].

Internationalization makes companies focus on the long supply chain. This leads to a waste of inventory costs and bullwhip effect, as well as higher overall costs. Lack of supplier support and cost-sharing in research and development practices will lead to an unsustainable supply chain. These are some of the problems faced by car manufacturers in the world. However, there are social, economic and environmental problems that sustainable supply chain management deals with. The environment is the main focus of the sustainable supply chain and is most often highlighted in the media. That is why the CCI, which is the environmental side of the SSCM, is the main focus of this document.

On the other hand, focusing solely on the environmental dimension will not bring the sustainability of the supply chain on its own. Economic and social aspects are also inevitable. So companies need to explore both the social and economic aspects.

Industrialisation and changes in the business environment have led to the development of supply chain networks, which has become a critical issue in the business world today. Increased globalisation and outsourcing in industries have led industries to focus and compete in a supply chain and its management. Several trends in the supply chain have been observed so far. Hopkins states "In the 1980s, it was just-in-time production; in the 1990s, it was supply chain cooperation and outsourcing of supply activities; and in the 2000s, it was the application of the Internet, according to the supply chain thinker, David Simchi-Levi" (cited in Xia et al. 2011, p. 496) [23]. Today, the desired trend is to ensure sustainability within the supply chain. Seuring et al. (2008, p. 1545) defined sustainable supply chain management as "the management of material and information flows, as well as cooperation between companies along the supply chain, while taking into account the objectives of all three dimensions of sustainable development, i.e. economic, environmental and social and stakeholder requirements". These dimensions, as mentioned earlier, are economic, environmental and social [24].

Carter (2011) clarifies these dimensions and sustainability increases visibility with these words; "There are several factors for this increasing visibility of sustainability, including the supply and demand characteristics surrounding energy 
consumption, an increased understanding of climate change science, and greater transparency regarding both environmental and social actions of organizations" [25].

Webster (2006) defines this importance with these words "With a decisively significant impact on operational efficiency, automotive supply chain management becomes one of the key elements for the survival or success of the industry itself" [26].

Recently, many researches and studies on the concept of CCI have been carried out in the literature. The history of its ecological supply chain is inspired by research into reverse supply studies in the 1990s [27].

The idea of THEA first emerged in research called "environmentally responsible construction" by Michigan State University in 1996 (Wang and Luo, 2010). Later, van Hoek (1999) realized the relationship between environmental study in logistics and reverse logistics, which was then extended to the entire study chain (McKinnon, 2010). HSU and Hu (2008) defined CCI: "CCI is as an approach to improving the performance of processes and products in accordance with the requirements of environmental regulations". Hervani et al. (2005) explains CCI as " $\mathrm{CCI}$ is the summation of green markets, green construction/material management, green Distribution/Marketing and Reverse Logistics" (referred to et al. Luthra, 2014, p.23). In short, the CCI includes traditional supply chain management applications that incorporate environmental criteria [28]-[36].

Although the concept of CCI was introduced in the 1990s, it is still a new concept in underdeveloped or developing countries such as China, Turkey, India, etc. It is therefore vital to analyze examples of CCI applications in these countries to see how successful these countries are in exploiting CCI in their main industries.

Measuring CCI performance is a very difficult task for businesses. Measuring environmental performance between enterprises is much more difficult than measuring one of them. Lack of systems, non-standard data and weak technological integration, together with cultural and organisational differences, are the reasons that make it difficult to measure the environmental performance of organisations. Regulations, competitiveness and marketing are the main mandatory reasons for measuring performance for the management of the green supply chain. The main objectives of performance measurement for the management of the green supply chain are internal control and analysis and external reporting. These external reporting, control and analysis activities are necessary for better business management and continuous improvement of the business [30].

\section{Conclusions}

Environmental performance assessment is achieved through the Environmental Performance Assessment (Environmental Performance Assessment), which is defined as "an internal process and management tool designed to provide management with reliable and verifiable information on an ongoing basis to deter- 
mine whether an organisation's environmental performance meets the criteria set by the organisation's management" [31]. In addition, Simpson et al. (2007) stated that the challenges of the green supply chain as a customer have significant potential to impose improvements in the environmental management practices of its suppliers, to introduce environmentally sound technologies and to work with suppliers to share knowledge and jointly develop more sustainable products and processes. From the customer's point of view, this may require a more hierarchical approach to the issue of supplier greening; that is, it is expected that some suppliers will be more or less responsive than others. From the supplier's point of view, this may present advantages and difficulties in its efforts to meet a new and potentially underdeveloped set of environmental performance requirements. From a governmental point of view, this may require a more collaborative approach to working with organisations as a challenge to achieve the objectives of global sustainability increases [32].

As discussed, environmental issues have become more important to all companies and have caused supply chain methods to change. Therefore, traditional supply chain management no longer applies in the competitive market. In addition, legislative pressures and consumer demands are also reasons for the CCI [33].

Traditional supply chain management (SDS) focuses on the economy as a target. On the other hand, in addition to the target economy, the IIA pays more attention to ecology, as mentioned in previous sections. The traditional supply chain does not pay attention to the toxicological effects of humans, while the management of the green supply chain is green and ecologically optimised [34]. Only the management of production and distribution from the raw material to the final destination, which is the traditional management of the supply chain, is no longer enough. Traditional supply chain management does not focus on the dangerous effects of the environment on production and distribution. The main concern is the monitoring and control of finished products.

According to Hervani et al. (2005), the CCI contains green markets, green construction/material management, green distribution/marketing and reverse logistics [35]. CCI should contain six parts throughout the chain from design to final process recycling which can be registered as green construction, green market, green design, green marketing and distribution, and green recycling [36] [37].

\section{Acknowledgements}

All authors would like to thank the University of West Attica and specifically the Post Graduate Program of Studies (MSc) "New Technologies in Shipping and Transport", for the financial support provided to them to undertake this research project.

\section{Conflicts of Interest}

The authors declare no conflicts of interest regarding the publication of this paper. 


\section{References}

[1] Brusati, L. (2011) Tofas and the Internationalization of the Turkish Car Industry. Caso, 1, 1-14.

[2] Fındıkçığlu, G. and Yıldırım, B. (2010) Turkish Automotive Industry 2010. Turkiye Sinai Kalkinma Bankasi AS Research, Istanbul.

[3] Charter, M., et al. (2001) R\&D Report-Supply Chain Strategy and Evaluation. The Sigma Project.

http://www.projectsigma.co.uk/rndstreams/rd supply chain strategy.pdf

[4] Blain, P. (2012) International Organization of Motor Vehicle Manufacturers (OICA). Geneva, 7 March 2012.

[5] Ericsson, R., et al. (2010) From Build-to-Order to Customise-to-Order. Advancing the Automotive Industry by Collaboration and Modularity.

http://www.iao.fraunhofer.de/images/downloadbereich/300/advancing-the-automot iveindustry-by-collaboration-and-modularity.pdf

[6] Chaves, G.D.L.D. and Alcântara, R.L.C. (2006) Reverse Logistics and The Relation between Industry and Retail in the after in the after-Sale Reverse. Third International.

[7] http://manufacturingbenchmarks.com/mpigroup/wpcontent/uploads/2012/06/Auto motiveSuppliers WP US.pdf

[8] Fiksel, J. (1996) Design for Environment: Creating Eco-Efficient Products and Processes. McGraw-Hill, New York, 34-36.

[9] Hebeler, P. (2003) Achieving Automotive Supplier Excellence: Flawless Delivery Execution. http://www.oracle.com/us/industries/automotive/018918.pdf

[10] European Union (2005) Directive 2005/32/EC of the European Parliament and of The Council. Official Journal of the European Union.

http://ec.europa.eu/enterprise/policies/european-standards/harmonisedstandards/e codesign/index en.htm

[11] Eup Eco Design (2012) Eco-Design Requirements for Energy-Using Products (EuP).

[12] Euractiv (2006) http://www.euractiv.com

[13] Geraghty, K. (2008) REACH: Implications of Europe's New Chemicals Policy for PCB Fabricators. Circuit World, 34, 14-18. https://doi.org/10.1108/03056120810918079

[14] Chen, Y.J. and Sheu, J.B. (2009) Environmental-Regulation Pricing Strategies for Green Supply Chain Management. Transportation Research Part E: Logistics and Transportation Review, 45, 667-677. https://doi.org/10.1016/j.tre.2009.04.010

[15] Christopher, M. (2005) Logistics and Supply Chain Management. Pearson Education, London.

[16] Master's Thesis, University of Halmstad.

http://www.divaportal.org/smash/record.jsf?pid=diva2:239714

[17] http://www.askam.com.tr/v2/default.aspx

[18] EDI Basics (2012) EDI for the Automotive Industry. http://www.edibasics.co.uk/edi-by-industry/the-automotive-industry

[19] Büyüközkan, G. and Vardaloğlu, Z. (2008) Yeşil Tedarik Zinciri Yönetimi. Lojistik Dergisi, 8, 66-73.

[20] Ford-Otosan (2012). http://www.fordotosan.com.tr 
[21] De Craecker, F. and De Wulf, L. (2009) Integration of Green Marketing within the Automotive Industry-A Case Study of Four Car Manufacturers on the Belgian Market. Doctoral Dissertation, Halmstad University, Halmstad.

[22] CAEF (2013) Going Abroad: Internationalization in the Automotive Industry. CAEF Automotive Castings Section Meeting, Frankurt, 20 March 2013, 1-30.

[23] Hopkins, M.S. (2010) Your Next Supply Chain: Interview with David Simchi-Levi and Charles H. Fine. MIT Sloan Management Review, 51, 17-24.

[24] Gilbert, S. (2000) Greening Supply Chain: Enhancing Competitiveness through Green Productivity. Asian Productivity Organization, Tokyo.

[25] Carter, C.R. and Easton, P.L. (2011) Sustainable Supply Chain Management: Evolution and Future Directions. International Journal of Physical Distribution \& Logistics Management, 41, 46-62. https://doi.org/10.1108/09600031111101420

[26] (2006) 3rd Conference on Production Research-Americas' Region 2006 (ICPR-AM06).

[27] Brandt, J.R. and Taninecz, G. (2008) Turning Toward Success for Automotive Suppliers. Microsoft Corporation, Redmond.

[28] Ginsberg, J.M. and Bloom, P.N. (2004) Choosing the Right Green Marketing Strategy. MIT Sloan Management Review, 46, 79-84.

[29] Hawks, K. (2006) What Is Reverse Logistics? Reverse Logistics Magazine, Winter/Spring.

[30] Hervani, A.A., Helms, M.M. and Sarkis, J. (2005) Performance Measurement for Green Supply Chain Management. Benchmarking. An International Journal, 12, 330-353. https://doi.org/10.1108/14635770510609015

[31] Diabat, A. and Govindan, K. (2011) An Analysis of the Drivers Affecting the Implementation of Green Supply Chain Management. Resources, Conservation and Recycling, 55, 659-667. https://doi.org/10.1016/j.resconrec.2010.12.002

[32] Green Purchasing Guide (2011) Commitment to Buy Green. Greening Greater Toronto, October 2011, 1-8.

http://www.partnersinprojectgreen.com/files/GreenPurchasingGuide.pdf

[33] Deans, I. (1999) An Approach to the Environmental Management of Purchasing in the Utilities Sector. Eco-Management and Auditing, 6, 11-17. https://doi.org/10.1002/(SICI)1099-0925(199903)6:1<11::AID-EMA95>3.0.CO;2-Y

[34] Beamon, B.M. (1999) Designing the Green Supply Chain. Logistics Information Management, 12, 332-342. https://doi.org/10.1108/09576059910284159

[35] Etkin, L.P., Helms, M.M., Turkkan, U. and Morris, D.J. (2000) The Economic Emergence of Turkey. European Business Review, 12, 64-75.

https://doi.org/10.1108/09555340010318655

[36] Bai, C. and Sarkis, J. (2010) Integrating Sustainability into Supplier Selection with Grey System and Rough Set Methodologies. International Journal of Production Economics, 124, 252-264. https://doi.org/10.1016/j.ijpe.2009.11.023

[37] Dowie, T. (1994) Green Design. World Class Design to Manufacture, 1, 32-38. https://doi.org/10.1108/09642369210063045 